\title{
Effects of Milk Products Fermented by Bifidobacterium longum on Blood Lipids in Rats and Healthy Adult Male Volunteers
}

\author{
J. Z. Xiao*, S. Kondo*, N. Takahashi*, K. Miyaji”, K. Oshida†, A. Hiramatsu*, \\ K. Iwatsuki ${ }^{\star}$, S. Kokubo*, and A. Hosonoł \\ *Food Research and Development Laboratory, \\ †Nutritional Science Laboratory, \\ Morinaga Milk Industry Co., Ltd., \\ Zama 228-8583, Japan; $\ddagger$ Department of Agriculture, \\ Shinshu University, \\ Nagano-Minamiminowa 399-4598, Japan
}

\section{ABSTRACT}

The effects of milk products fermented by Bifidobacterium longum strain BL1, a probiotic strain, on blood lipids in rats and humans were studied. Rats were fed a cholesterol-enriched experimental diet, supplemented with lyophilized powders of 1) acid milk (control), 2) milk fermented with a mixed culture of ordinary yogurt starters composed of Streptococcus thermophilus and Lactobacillus delbrueckii subsp. bulgaricus (SL), and 3) bifidobacterium milk fermented with the probiotic B. longum strain BL1, respectively. The bifidobacterium milk feeding brought about significant lowering of the serum concentrations of total cholesterol, low-density lipoprotein cholesterol, and triglycerides, in comparison with the control, while no change in high-density lipoprotein cholesterol concentration was observed. On the other hand, supplementation with SL milk resulted in only slight, nonsignificant decreases in serum lipid concentrations in comparison with the control. In the human study, 32 subjects with serum total cholesterol ranging from 220 to $280 \mathrm{mg} / \mathrm{dl}$ were randomly assigned to two treatments: 1) intake of a low-fat drinking yogurt prepared with ordinary yogurt starters composed of $S$. thermophilus and L. delbrueckii subsp. bulgaricus ( $\mathrm{P}$ group) and 2) intake of a low-fat drinking yogurt prepared with the two ordinary yogurt starters plus $B$. longum strain BL1 (B-group). After intake for $4 \mathrm{wk}$ at $3 \times 100 \mathrm{ml} /$ day, reduction of serum total cholesterol was observed in approximately half of the B-group subjects; a particularly significant decrease in serum total cholesterol was found among subjects with moderate hypercholesterolemia (serum total cholesterol > $240 \mathrm{mg} / \mathrm{dl}$ ). However, the serum lipid concentrations

\footnotetext{
Received November 1, 2002.

Accepted February 26, 2003.

Corresponding author: J.Z. Xiao; e-mail: j_xiao@ morinagamilk.co.jp.
}

in the P-group subjects were almost stable during the experimental periods. The present results indicate the potential of the probiotic $B$. longum strain BL1 in serum lipid improvement.

(Key words: Bifidobacterium, blood lipid, fermented milk)

Abbreviation key: HDL = high density lipoprotein, $\mathbf{L D L}=$ low density lipoprotein, $\mathbf{I H D}=$ ischemic heart disease, $\mathbf{S L}=$ mixed culture of $S$. thermophilus and $L$. delbrueckii subsp. bulgaricus.

\section{INTRODUCTION}

A high level of serum total cholesterol is generally considered to be a risk factor for coronary heart disease and atherosclerosis in the USA, Europe, and Japan (Anderson et al., 1987; Law et al., 1994; Ross, 1993; Yamamoto et al., 1999). Reducing the level causes decreases in incidence and mortality of ischemic heart disease (IHD) and atherosclerosis (Frick et al., 1987; Mabuchi, 1999). Much attention has thus been drawn to different dietary ways of reducing the serum total cholesterol level.

Mann and Spoerry (1974) first reported a hypocholesterolemic effect in Maasai tribesmen of milk fermented by wild type starters. Thereafter, many studies have been performed in experimental animals and humans to elucidate the effect of fermented dairy products on serum cholesterol, especially with selected strains of lactic acid bacteria (see review of St-Onge et al., 2000). The mechanisms of the hypocholesterolemic activity of lactic acid bacteria have been proposed to involve inhibition of exogenous cholesterol absorption from the small intestine by the binding of cholesterol and bile acids with the bacterial cells, assimilation of cholesterol, as well as suppressing bile acid resorption by deconjugation as a function of the bacterial bile salt hydrolase activity (Gilliland et al., 1985; Danielson et al., 1989; Salminen and von Wright, 1993; De Smet et al., 1998). 
To guarantee a probiotic effect after administration, microorganisms should survive passage through the gastric juice and small intestine (Gilliland and Walker, 1990). Bifidobacterium longum strain BL1 was found to have a high tolerance for artificial gastric juice and bile (see Results). This strain was found to possess a strong bile salt hydrolase activity (unpublished data). It is thus suspected that strain BL1 would survive passage through the gastrointestinal tract and would function in vivo in cholesterol removal.

Based on the above, the present study was conducted to demonstrate the effect of milk fermented by B. longum strain BL1 on blood lipids in rats and humans.

\section{MATERIALS AND METHODS}

\section{Source and Maintenance of Cultures}

B. longum strain BL1 (MCC 1083) and yogurt starters of Streptococcus thermophilus and Lactobacillus delbrueckii subsp. bulgaricus were stock cultures of Morinaga Milk Industry Co., Ltd., Kanagawa, Japan. The culture of B. longum strain BL1 was maintained by subculture ( $10 \%$ inoculation) in $11 \%$ reconstituted skim milk containing $0.2 \%$ yeast extract at $37^{\circ} \mathrm{C}$ for 5 to $6 \mathrm{~h}$. The mixed culture of S. thermophilus and $L$. delbrueckii subsp. bulgaricus (SL) was maintained by subculture (3\% inoculation) in $10 \%$ reconstituted skim milk at $37^{\circ}$ for $5 \mathrm{~h}$. Subcultures were stored at $4^{\circ} \mathrm{C}$ between transfers. Freshly prepared seed cultures were used for production of yogurts.

\section{Measurement of Gastric Juice and Bile Tolerance}

The culture of $B$. longum strain BL1 was prepared as described above. To $100 \mathrm{ml}$ artificial gastric juice (containing $0.2 \%$ pepsin, $0.35 \%$ sodium chloride, adjusted to $\mathrm{pH} 3.0$ by $\mathrm{HCl}$ ), $0.01 \mathrm{ml}$ of culture was added, and the mixture was mixed and incubated at $37^{\circ} \mathrm{C}$ for 1.5 to $2.0 \mathrm{~h}$. The $\mathrm{pH}$ of the mixture was 3.04 , and incubation was stopped by adding an equal volume of cooled $10 \%$ pasteurized reconstituted skim milk. As a control, $0.01 \mathrm{ml}$ of culture was incubated in $100 \mathrm{ml}$ of $0.86 \%$ sodium chloride solution $(\mathrm{pH} 6.5)$ at $37^{\circ} \mathrm{C}$ for 2 h. Viable counts were determined immediately after incubation on Reinforced Clostridial Agar (Oxoid, England) under anaerobic conditions at $37^{\circ} \mathrm{C}$ for $72 \mathrm{~h}$. The rate of gastric juice tolerance was calculated as follows:

$$
\begin{gathered}
\text { Tolerance rate }(\%)=\left[(\mathrm{cfu} / \mathrm{ml})_{\text {gastric juice }} /\right. \\
\left.(\mathrm{cfu} / \mathrm{ml})_{\text {control }}\right] \times 100
\end{gathered}
$$

For the bile tolerance test, $0.01 \mathrm{ml}$ of culture was added to $100 \mathrm{ml}$ of $10 \%$ pasteurized reconstituted skim milk containing 0 to $1.6 \%$ of oxgall (Sigma Chemical Co., St. Louis, MO), and the mixture was incubated at $37^{\circ} \mathrm{C}$ for either 5 or $16 \mathrm{~h}$. The control was a culture without incubation. Viable counts were determined as described above, and the rate of bile tolerance was calculated as follows:

$$
\text { Bile tolerance rate }=(\mathrm{cfu} / \mathrm{ml})_{\mathrm{bile}} /(\mathrm{cfu} / \mathrm{ml})_{\text {control }}
$$

\section{Animal Experiment}

For the production of SL milk, bifidobacterium milk, and control acid milk, skim milk base (containing $11 \%$ skim milk powder, $1 \%$ glucose, and $0.2 \%$ yeast extract) was pasteurized at $90^{\circ} \mathrm{C}$ for $10 \mathrm{~min}$ prior to fermentation, cooled to $40^{\circ} \mathrm{C}$, and then divided into three parts. One portion was inoculated with a $1 \%(\mathrm{w} / \mathrm{w})$ mixed seed culture of ordinary lactic acid bacterial starters composed of $S$. thermophilus and L. delbrueckii subsp. bulgaricus for SL milk, and the second portion was inoculated with a $1 \%(\mathrm{w} / \mathrm{w})$ seed culture of $B$. longum strain BL1 for bifidobacterium milk, respectively. Each of the inoculated mixes was incubated at $37^{\circ} \mathrm{C}$ until it reached $\mathrm{pH} 4.5$ and then cooled to $4^{\circ} \mathrm{C}$. The products were lyophilized for experimental diets. Prior to lyophilization, the fermented milks were partially neutralized by mixing with equal volumes of pasteurized $20 \%$ skim milk base to improve bacterial survival when frozen. Preparation of lyophilized powder was carried out three times each for SL milk and bifidobacterium milk. Total viable cfu were $3.8 \pm 0.9 \times 10^{8}$ / $\mathrm{g}$ and $4.1 \pm 0.7 \times 10^{8} / \mathrm{g}$ of lyophilized powder for SL milk and bifidobacterium milk, respectively. Lactic acid was added to the third portion of milk to $\mathrm{pH}$ 4.5 for control acid milk, which was neutralized and lyophilized in the same manner as the fermented milks.

Twenty-one rats (Male Sprague-Dawley), that were 4 wk old, were purchased from Japan SLC Co., Ltd., Shizuoka, Japan. After being given a standard diet (F2, Oriental Yeast Co., Ltd., Tokyo, Japan) for $1 \mathrm{wk}$, they were divided into three groups (seven each) balanced according to BW and randomized to experimental diets that were supplemented with lyophilized powders of SL milk, bifidobacterium milk, or control acid milk. They were housed in an air-conditioned room at $25 \pm 2^{\circ} \mathrm{C}$ with $55 \pm 5 \%$ humidity on a $12 \mathrm{~h}$ light-dark cycle (light from 0800 to $2000 \mathrm{~h}$ and dark from 2000 to $0800 \mathrm{~h}$ ). Water was freely available, and the experimental diets were given at approximately $20 \mathrm{~g} / 100 \mathrm{~g}$ BW per day. 
Table 1. Composition and cfu of lactic acid bacteria of experimental $\operatorname{diets}^{1}$

\begin{tabular}{|c|c|c|c|}
\hline & \multicolumn{3}{|c|}{ Composition $(\%)$} \\
\hline & $\begin{array}{c}\text { Acid milk } \\
\text { (control) }\end{array}$ & $\begin{array}{l}\text { SL } \\
\text { milk }\end{array}$ & $\begin{array}{c}\text { Bifidobacterium } \\
\text { milk }\end{array}$ \\
\hline Casein & 6.92 & 6.92 & 6.92 \\
\hline Corn starch & 33.78 & 33.78 & 33.78 \\
\hline$\alpha$-Corn starch & 11.49 & 11.49 & 11.49 \\
\hline Sucrose & 7.41 & 7.41 & 7.41 \\
\hline Cellulose & 5.00 & 5.00 & 5.00 \\
\hline Soybean oil & 9.84 & 9.84 & 9.84 \\
\hline AIN-93M mineral mixture & 3.50 & 3.50 & 3.50 \\
\hline AIN-93 vitamin mixture & 1.00 & 1.00 & 1.00 \\
\hline Choline bitartrate & 0.25 & 0.25 & 0.25 \\
\hline L-Cystine & 0.18 & 0.18 & 0.18 \\
\hline$t$-Butylhydroquinone & 0.0008 & 0.0008 & 0.0008 \\
\hline Cholesterol & 0.50 & 0.50 & 0.50 \\
\hline Sodium cholate & 0.125 & 0.125 & 0.125 \\
\hline Lyophilized acid milk & 20.00 & 0.00 & 0.00 \\
\hline Lyophilized SL milk & 0.00 & 20.00 & 0.00 \\
\hline Lyophilized bifidobacterium milk & 0.00 & 0.00 & 20.00 \\
\hline Total & 100.00 & 100.00 & 100.00 \\
\hline \multicolumn{4}{|c|}{ Counts of viable lactic acid bacteria (cfu/g $\left.\operatorname{diet}^{2}\right)$} \\
\hline Before administration & - & $8.0 \pm 3.0 \times 10^{7}$ & $4.9 \pm 1.1 \times 10^{7}$ \\
\hline After administration & - & $3.9 \pm 2.0 \times 10^{7}$ & $3.1 \pm 2.2 \times 10^{6}$ \\
\hline
\end{tabular}

The composition of the experimental diet was based on AIN-93M, with protein content of $14 \%$ (Table 1). The lyophilized powder was added to the diet at the expense of sucrose and starch. Since large numbers of the lyophilized cells described above were found to die after being combined with the diet, presumably due to the moisture of the diet, the major components (casein, corn starch, $\alpha$-corn starch, sucrose, cellulose, and mineral mixture) were oven-dried at $60^{\circ} \mathrm{C}$ overnight prior to diet preparation. Diet materials, except lyophilized powders, were mechanically mixed, subdivided, and packaged in sealed aluminum bags and stored in a refrigerator $\left(4^{\circ} \mathrm{C}\right)$ until use. The lyophilized powders were mixed with the base diet just before being given to the animals, and freshly prepared diets were replaced daily at 1600 to $1700 \mathrm{~h}$ to prevent loss of bacterial survival during storage and feeding. Counts of viable lactic acid bacteria in the diets were between $10^{7}$ to $10^{8} \mathrm{cfu} / \mathrm{g}$ in the freshly prepared diets but decreased to approximately half and 1/10 of the original counts after administration for SL milk and bifidobacterium milk, respectively (Table 1).

The assigned diets were given to the rats for $3 \mathrm{wk}$. Feed intake was measured daily, and BW was measured weekly. To determine levels of fecal steroids, fecal samples were collected for the last $2 \mathrm{~d}$ of the experimental period, freeze-dried, and then stored at $-40^{\circ} \mathrm{C}$ until analysis. At the end of the $3 \mathrm{wk}$ feeding period, the rats were deprived of diet for a minimum of $16 \mathrm{~h}$ and then anesthetized with an intraperitoneal injection of sodium pentobarbital (Nembutal, Abbott Laboratories, Chicago, IL, USA) at $50 \mathrm{mg} / \mathrm{kg}$ BW. Blood samples were collected from the abdominal aorta, placed in sterile tubes, and centrifuged at 2000 $\times g$ for $15 \mathrm{~min}$ at $4^{\circ} \mathrm{C}$. The obtained serum samples were analyzed for total cholesterol, high-density lipoprotein (HDL) cholesterol, triglycerides, and phospholipids using Cholesterol E Test Wako, HDL-cholesterol Test Wako, Triglyceride G Test Wako, and Phospholipid C Test Wako (Wako Pure Chemical Industries, Ltd., Tokyo, Japan) test kits, respectively. Low-density lipoprotein (LDL) cholesterol was calculated using the equations of Friedewald et al. (1972), as described later.

Fecal total bile acids were determined by the methods of Hashimoto et al. (1999) with some modification. Milled freeze-dried feces $(0.05 \mathrm{~g})$ were extracted twice with $3.5 \mathrm{ml}$ ethanol at $80^{\circ} \mathrm{C}$ for $1 \mathrm{~h}$. After two extractions, the ethanol was evaporated under $\mathrm{N}_{2}$ gas at $50^{\circ} \mathrm{C}$, and the residue was dissolved in $2.5 \mathrm{ml}$ ethanol. The amounts of total bile acids were analyzed with a commercial test kit (Total Bile Acid Test Wako, Wako Pure Chemical Industries, Ltd., with a detection sensitivity level of 10 to $50 \mu \mathrm{mol} / \mathrm{l}$ of bile acids).

\section{Human Study}

The bifidobacterium and placebo drinking yogurts were produced in the Research and Information Cen- 
Table 2. Properties and lactic acid bacterial numbers of bifidobacterium

\begin{tabular}{lccccc}
\hline & \multicolumn{2}{c}{ Bifidobacterium yogurt } & & \multicolumn{2}{c}{ Placebo yogurt } \\
\cline { 2 - 3 } \cline { 5 - 6 } & Day 0 & Day 9 & & Day 0 & Day 9 \\
\hline pH & $4.46 \pm 0.04$ & $4.26 \pm 0.01$ & & $4.33 \pm 0.13$ & $4.25 \pm 0.15$ \\
$\begin{array}{l}\text { Acidity (lactic acid, \%) } \\
\text { cfu/ml of: }\end{array}$ & $0.72 \pm 0.10$ & $0.77 \pm 0.05$ & & $0.74 \pm 0.12$ & $0.78 \pm 0.05$ \\
$\quad \begin{array}{l}\text { Bifidobacterium } \\
\text { Streptococcus }\end{array}$ & $3.7 \pm 1.1 \times 10^{8}$ & $1.9 \pm 0.2 \times 10^{8}$ & & $\mathrm{ND}^{1}$ & $\mathrm{ND}$ \\
Lactobacillus & $3.4 \pm 0.7 \times 10^{8}$ & $3.3 \pm 0.8 \times 10^{8}$ & & $4.9 \pm 0.6 \times 10^{8}$ & $5.0 \pm 1.3 \times 10^{8}$ \\
\hline
\end{tabular}

${ }^{1} \mathrm{ND}=$ Not determined.

ter of Morinaga Milk Industry Co., Ltd. The bifidobacterium yogurt was fermented with a starter of $B$. longum strain BL1 in the presence of ordinary lactic acid bacterial starters composed of $S$. thermophilus and L. delbrueckii subsp. bulgaricus. The placebo yogurt was fermented with the same ordinary lactic acid bacterial starters employed in preparation of the bifidobacterium yogurt. The fermented milks were then homogenized aseptically at $15 \mathrm{MPa}$ to make drinking yogurts. The properties and cfu of the products are shown in Table 2. The bifidobacterium yogurt contained more than $10^{8}$ cfu of $B$. longum strain BL1 when tested on both d 0 and d 9 after production. One hundred grams of each of the bifidobacterium and placebo yogurts had an energy content of approximately $50 \mathrm{kcal}$ and contained $3.0 \mathrm{~g}$ of protein, $8.2 \mathrm{~g}$ of carbohydrate, and $0.6 \mathrm{~g}$ of milk fat. Products were prepared weekly and distributed to the participating subjects in plastic bottles containing $100 \mathrm{ml}$, which were kept in a refrigerator at $4^{\circ} \mathrm{C}$.

Thirty-two volunteers participated in the study. The volunteers were healthy adult men deemed suitable for participation in the test on the basis of prior physical examination, serum cholesterol level, and medical history. The volunteers were informed about the purpose and detailed procedure of the experiments. A 2wk pre-intake run-in period was arranged, during which the volunteers were advised to maintain their ordinary living habits including their diets, except for restricted consumption of fermented milk and pickles. After the pre-intake run-in period, serum lipids were determined from blood samples taken before breakfast after the subjects had fasted overnight. Thirty-two healthy male subjects whose serum total cholesterol levels were within the range of 220 to $280 \mathrm{mg} / \mathrm{dl}$ at the preintake blood sampling were selected. The subjects were divided into two groups matched for serum total cholesterol and age and randomized to either the bifidobacterium yogurt group (B-group) or placebo yogurt group (P-group). Characteristics of the subjects in the two groups are presented in Table 3.

The study was planned and carried out in accordance with the Declaration of Helsinki. The study protocol was approved and controlled by the Local Ethics Committee of Morinaga Milk Industry Co., Ltd.

Since the present study was a pilot study for future long-term study, it was designed simply as a shortterm, single-blind, parallel group study. Starting 1 wk after the pre-intake blood sampling, subjects were instructed to consume $3 \times 100 \mathrm{ml}$ of either bifidobacterium or placebo yogurt daily as a part of their habitual meals (breakfast, lunch, and dinner) for $4 \mathrm{wk}$. During the intake period, subjects had to fill in a questionnaire on compliance, intake of medicine, alcohol consumption, and BW (once a week, wearing indoor clothing without shoes). Blood samples for the measurement of glucose and serum lipids were taken after fasting overnight before breakfast during wk 4 .

Blood samples were drawn from an antecubital vein. The analysis of the collected blood samples was performed at BML Co. Ltd., Tokyo, Japan. Total cholesterol, HDL-cholesterol, and triglycerides were measured with a 7450 Automatic Analyzer (Hitachi Co., Ltd., Tokyo, Japan). Blood glucose was measured with

Table 3 Characteristics of subjects ${ }^{1}$

\begin{tabular}{lccccc}
\hline & \multicolumn{2}{c}{ B-group } & & \multicolumn{2}{c}{ P-group } \\
\cline { 2 - 3 } \cline { 6 - 6 } & Mean $\pm \mathrm{SE}$ & Range & & Mean \pm SE & Range \\
\hline Serum total cholesterol, mg/dl & $243.9 \pm 15.2$ & $221-272$ & & $243.9 \pm 15.4$ & $223-277$ \\
Age, yr & $43.8 \pm 8.3$ & $31-59$ & & $43.9 \pm 7.8$ & $28-60$ \\
BW, kg & $68.7 \pm 6.5$ & $55.6-81.8$ & & $67.2 \pm 7.6$ & $55.4-78.8$ \\
\hline
\end{tabular}

${ }^{1}$ All values were measured at the pre-intake blood sampling. 
Table 4. Bile tolerance of Bifidobacterium longum BL-1

\begin{tabular}{llc}
\hline \multirow{2}{*}{$\begin{array}{l}\text { Concentration } \\
\text { of oxgall }(\%)\end{array}$} & \multicolumn{2}{c}{ Rate of bile tolerance } \\
\cline { 2 - 3 } & $5 \mathrm{~h}$ & $16 \mathrm{~h}$ \\
\hline 0.0 & 1.33 & 3.31 \\
0.4 & 1.24 & 2.02 \\
1.6 & 1.08 & 0.81 \\
\hline
\end{tabular}

${ }^{1}$ Bile tolerance was tested in skim milk containing different concentrations of oxgall at $37^{\circ} \mathrm{C}$ for different times. As described in Materials and Methods. Rate of bile tolerance was calculated as follows: Bile tolerance rate $=(\mathrm{cfu} / \mathrm{ml})_{\text {bile }} /(\mathrm{cfu} / \mathrm{ml})_{\text {control }}$.

a JCA-BM12 Automatic Analyzer (JEOL. Ltd., Tokyo, Japan). LDL-cholesterol was computed according to Friedewald's formula (Friedewald et al., 1972):

LDL-cholesterol $=$ total cholesterol - HDL-cholesterol - (serum triglycerides/ 5).

\section{Statistical Analysis}

The experimental data are presented as the means and standard errors of the means. Dunnett's $t$-test for multi-comparison was applied to determine the statistical significance of the difference in effects among the three groups in the animal study, using the JMP software package, version 4.05J (SAS Institute, Japan), with the significance level set at $P<0.05$. The paired Student's $t$-test was conducted with Microsoft Excel, version 97, to determine the statistical significance of the difference in effects between the two groups in the human study.

\section{RESULTS}

\section{Gastric Juice and Bile Tolerance}

High tolerance of strain BL1 to gastric juice was observed. Incubation in artificial gastric juice at $\mathrm{pH}$ 3.0 and $37^{\circ} \mathrm{C}$ for 1.5 and $2.0 \mathrm{~h}$ yielded tolerance rates of 32.4 and $11.3 \%$, respectively. The strain showed also a high tolerance to bile (Table 4). Multiplication of the strain in skim milk with or without bile was very slow, probably due to the restriction in nutrients. However, complete survival was observed after $5 \mathrm{~h}$ incubation in the presence of oxgall at 0.4 and $1.6 \%$. More than half of the bacterial cells survived after 16 $\mathrm{h}$ incubation in $1.6 \%$ oxgall.

\section{Animal Experiment}

The effects of the fermented milks on BW gain, feed intake, and feed efficiency are presented in Table 5. The mean BW gain of the bifidobacterium milk group was slightly higher than those of the other two groups, but the difference was not statistically significant $(P$ $>0.05$ ).

The effects of fermented milks on serum lipids are shown in Table 6 . The mean serum concentrations of total cholesterol and triglycerides of the group fed bifidobacterium milk were lower than those of the control group $(P<0.01)$ and the group fed SL milk $(P<$ $0.05)$. Serum LDL-cholesterol was reduced $(P<0.05)$ by the diet containing bifidobacterium milk in comparison with the control. HDL-cholesterol, and phospholipid concentrations were unaffected by bifidobacterium milk. Supplementation of the diets with SL milk yielded only slight, nonsignificant decreases in serum lipids.

Concentrations of fecal total bile acid were $1.70 \pm$ $0.55,2.07 \pm 0.41$, and $2.16 \pm 0.26 \mathrm{mg} / \mathrm{g}$ of feces for the groups fed acid milk (control), SL milk, and bifidobacterium milk, respectively. Supplementation of the diets with SL milk or bifidobacterium milk resulted in a trend toward increased bile acid excretion in feces, but this effect was not statistically significant in comparison to that with control acid milk $(P=0.187)$ and for SL milk $(P=0.068)$ and bifidobacterium milk, respectively).

\section{Human Study}

At wk 4, all subjects completed the study. The mean $\mathrm{BW}$ were $69.0 \pm 6.7$ and $67.3 \pm 7.5 \mathrm{~kg}$ for the bifidobacterium yogurt (B-) group and placebo yogurt (P-)

Table 5. Body weight and feed intake of rats fed on experimental diets containing freeze-dried milk products.

\begin{tabular}{lccc}
\hline & $\begin{array}{c}\text { Acid milk } \\
\text { (control) }\end{array}$ & $\begin{array}{c}\text { SL } \\
\text { milk }^{1}\end{array}$ & $\begin{array}{c}\text { Bifidobacterium } \\
\text { milk }\end{array}$ \\
\hline Initial BW, g & $136.7 \pm 5.6$ & $136.7 \pm 5.2$ & $136.6 \pm 5.5$ \\
Final BW, g & $275 \pm 21.9$ & $267.9 \pm 20.1$ & $281.3 \pm 22.8$ \\
BW gain, g/d & $6.9 \pm 1.0$ & $6.6 \pm 0.8$ & $7.2 \pm 1.1$ \\
Feed intake, g/d & 20.0 & 19.2 & 19.9 \\
Feed efficiency & 0.35 & 0.34 & 0.36 \\
\hline
\end{tabular}

${ }^{1} \mathrm{SL}=$ mixed culture of $S$. thermophilis and L. delbrueckii subsp. bulgaricus.

${ }^{2}$ Feed efficiency $=$ BW gain/feed intake. 
Table 6. Serum lipid concentrations of rats fed experimental diets containing freeze-dried milk powders. ${ }^{1}$

\begin{tabular}{llll}
\hline $\begin{array}{l}\text { Serum lipid } \\
\text { concentration }(\mathrm{mg} / \mathrm{dl})\end{array}$ & $\begin{array}{l}\text { Acid milk } \\
\text { (control) }\end{array}$ & SL milk & $\begin{array}{l}\text { Bifidobacterium } \\
\text { milk }\end{array}$ \\
\hline Total cholesterol $^{3}$ & $0.82 \pm 0.09^{\mathrm{a}}$ & $0.79 \pm 0.14^{\mathrm{a}}$ & $0.64 \pm 0.07^{\mathrm{b}}$ \\
HDL-cholesterol $^{3}$ & $0.33 \pm 0.08^{\mathrm{a}}$ & $0.33 \pm 0.04^{\mathrm{a}}$ & $0.31 \pm 0.07^{\mathrm{a}}$ \\
LDL-cholesterol $^{4}$ & $0.34 \pm 0.11^{\mathrm{a}}$ & $0.31 \pm 0.13^{\mathrm{ab}}$ & $0.20 \pm 0.07^{\mathrm{b}}$ \\
Triglyceride $_{\text {Phospholipid }}$ & $0.76 \pm 0.11^{\mathrm{a}}$ & $0.74 \pm 0.10^{\mathrm{a}}$ & $0.66 \pm 0.07^{\mathrm{b}}$ \\
\hline
\end{tabular}

\footnotetext{
${ }^{1}$ Data are presented as means and standard errors of the means.

${ }^{2} \mathrm{SL}=$ mixed culture of $S$. thermophilus and L. delbrueckii subsp. bulgaricus.

${ }^{3} \mathrm{HDL}=$ high density lipoprotein

${ }^{4} \mathrm{LDL}=$ low density lipoprotein as calculated by Friedewald's equation (Friedewald et al., 1972): (LDL = Serum total cholesterol-HDL-cholesterol-triglycerides/5).

${ }^{\mathrm{a}, \mathrm{b}}$ Mean values within a row not sharing a common superscript letter were significantly different. $P<$ 0.05 (multi-complicated Dunnett's $t$-test).
}

group, respectively. Only minor fluctuation in BW, not related to treatment, was observed. Physical examinations of all subjects performed at the time of blood sampling showed no abnormalities.

Table 7 shows the average values of serum lipids before and after the experimental diet intake for the 32 subjects. No significant change was found in serum lipid concentration during the experimental period, for both the B-group and P-group, although there was a trend toward reduction in the B-group. When the 16 subjects in the B-group were analyzed individually, most showed reduced total cholesterol levels. Considering up to $5 \%$ as an acceptable variation according to the laboratory method, we found that in the Bgroup, five subjects did not vary (had a total cholesterol variation less than 5\%), eight subjects showed a reduction (more than 5\%), and three subjects showed an increase (more than 5\%) of their cholesterol levels. On the other hand, there were 14 subjects without change, one subject with a reduction, and one subject with an increase in cholesterol level in the P-group.

The reduction trend of total cholesterol level in the B-group was more notable among subjects with moderate hypercholesterolemia. Table 8 shows the average values of serum lipids for those subjects with initial total cholesterol values over $240 \mathrm{mg} / \mathrm{dl}(\mathrm{n}=9)$. There was a reduction $(P<0.05)$ of total cholesterol after the experimental diet intake in the B-group. A significant difference was also observed between the B-group and P-group $(P<0.05)$. When each subject was analyzed individually, six subjects had a reduction (more than $5 \%$ ) and three subjects had no change (less than 5\%) of total cholesterol in the B-group, but seven subjects did not change, one subject had a reduction, and one subject had an increase in the P-group. Changes in the levels of HDL-cholesterol and LDL-cholesterol were correlated with the decrease or increase of total cholesterol in both the B-group and P-group, but the changes were not statistically significant. There was no significant change in the level of triglycerides during the experimental period.

There were no significant changes in serum glucose (data not shown). None of the subjects reported alterations in diet, alcohol intake, tobacco consumption, or physical activity during the study period. Both products were well tolerated, and compliance was good (more than 90\%) according to the questionnaire. One subject (B-group) stopped the sample intake for $1 \mathrm{wk}$

Table 7. Changes in human serum lipid levels after $4 \mathrm{wk}$ on experimental diets ${ }^{1}$

\begin{tabular}{|c|c|c|c|c|}
\hline & \multicolumn{2}{|c|}{ Placebo yogurt $(\mathrm{n}=16)$} & \multicolumn{2}{|c|}{ Bifidobacterium yogurt $(\mathrm{n}=16)$} \\
\hline & \multicolumn{2}{|c|}{ Mean $\pm \mathrm{SE}$} & \multicolumn{2}{|c|}{ Mean $\pm \mathrm{SE}$} \\
\hline & $-1 \mathrm{wk}$ & $4 \mathrm{wk}$ & $-1 \mathrm{wk}$ & $4 \mathrm{wk}$ \\
\hline Total cholesterol & $243.9 \pm 15.4$ & $243.1 \pm 20.1$ & $243.9 \pm 15.2$ & $237.3 \pm 15.9$ \\
\hline HDL-cholesterol $^{2}$ & $54.4 \pm 15.4$ & $51.8 \pm 15.6$ & $62.1 \pm 14.8$ & $59.3 \pm 13.6$ \\
\hline LDL-cholesterol $^{3}$ & $162.1 \pm 15.8$ & $159.4 \pm 22.0$ & $154 \pm 21.5$ & $149.1 \pm 14.0$ \\
\hline Triglyceride & $139.2 \pm 62.2$ & $142.1 \pm 52.6$ & $139.2 \pm 62.2$ & $131.9 \pm 45.3$ \\
\hline
\end{tabular}


Table 8. Changes in human serum lipid levels after 4 wk on experimental diets among subjects with an initial serum total cholesterol value over $240 \mathrm{mg} / \mathrm{dl}^{1}$

\begin{tabular}{|c|c|c|c|c|}
\hline & \multicolumn{2}{|c|}{ Placebo yogurt $(\mathrm{n}=9)$} & \multicolumn{2}{|c|}{ Bifidobacterium yogurt $(\mathrm{n}=9)$} \\
\hline & \multicolumn{2}{|c|}{ Mean $\pm \mathrm{SE}$} & \multicolumn{2}{|c|}{ Mean \pm SE } \\
\hline & $-1 \mathrm{wk}$ & $4 \mathrm{wk}$ & $-1 \mathrm{wk}$ & $4 \mathrm{wk}$ \\
\hline Total cholesterol & $253.8 \pm 13.4$ & $254.8 \pm 19.2$ & $254.1 \pm 11.8$ & $241.1 \pm 10.3^{*}$ \\
\hline HDL-cholesterol $^{2}$ & $51.9 \pm 9.8$ & $49.1 \pm 9.0$ & $63.1 \pm 12.6$ & $59.2 \pm 12.8$ \\
\hline LDL-cholesterol $^{3}$ & $171 \pm 8.7$ & $168.5 \pm 14.8$ & $162.3 \pm 18.3$ & $153.2 \pm 16.5$ \\
\hline Triglyceride & $154.4 \pm 57.6$ & $162.4 \pm 31.4$ & $143.3 \pm 61.4$ & $143.7 \pm 50.7$ \\
\hline
\end{tabular}

because of a business trip. One subject in the P-group and five subjects in the B-group claimed increased fecal frequency while participating in this study.

\section{DISCUSSION}

The results of the present study demonstrate that, as compared to traditional yogurt fermented with ordinary lactic acid bacteria, the bifidobacterium-fermented yogurt was effective in improving serum lipids in rats as well as in humans with moderate hypercholesterolemia. In the animal experiments, in comparison with the control, bifidobacterium milk diets resulted in significantly lower levels of serum total cholesterol, LDL-cholesterol, and triglyceride, but SL milk brought about only slight, nonsignificant changes. A single-blind, parallel group study with bifidobacterium yogurt and placebo yogurt in healthy men $(n=16)$ indicated a reduction trend in serum total cholesterol after intake of the bifidobacterium yogurt. A significant reduction of serum cholesterol was observed among subjects with moderate hypercholesterolemia (serum total cholesterol > $240 \mathrm{mg} / \mathrm{dl}$, $\mathrm{n}=9$ ).

The finding that bifidobacterium-fermented milk lowers serum total cholesterol concentrations in rats agrees with data from other studies involving various milk products containing selected strains of lactic acid bacteria. Akalin et al. (1997) demonstrated that yogurt fermented with $L$. acidophilus significantly reduced the serum total cholesterol concentration in mice, whereas yogurt fermented with ordinary yogurt starters containing $S$. thermophilus and $L$. delbrueckii subsp. bulgaricus did not. In experiments in rats, Beena and Prasad (1997) demonstrated that bifidus yogurt fortified with condensed whey lowered the cholesterol level more than did ordinary yogurt fortified with condensed whey. Reductions of serum total cho- lesterol and triglycerides were observed with selected strains including L. acidophilus (Danielson et al., 1989), L. reuteri (Taranto et al., 1998, De Roos et al., 1999), L. casei (Hashimoto et al., 1999), and L. gasseri (Usman and Hosono, 2000) in experimental animal studies.

The present animal studies indicated a slight, nonsignificant decrease in the concentration of HDL-cholesterol but a significant decrease in the concentrations of LDL-cholesterol in the group fed bifidobacteria in comparison with the control group. Because the LDL-cholesterol was calculated from values for serum total cholesterol, triglycerides, and HDL-cholesterol using the equations of Friedewald et al. (1972), the reduction in serum LDL-cholesterol concentrations would be expected. The present results related to HDL- and LDL- cholesterol generally agree with other findings (Aklain et al., 1997; Danielson et al., 1989; De Smet et al., 1998), although a decrease in total cholesterol was found with a simultaneous increase of HDL-cholesterol in some studies (Hashimoto et al., 1999; Taranto et al., 1998).

The mechanisms of serum lipid improvement have been suggested from in vitro and in vivo studies. In vitro experiments demonstrated that intestinal lactic acid bacteria have the capacity to assimilate and bind cholesterol as well as bile acids with the bacterial cells (Bottazzi et al., 1986; Gilliland et al., 1985, Hosono and Tono-oka, 1995). From these results, it is conceivable that serum total cholesterol is reduced by inhibiting absorption in the intestine as a result of the assimilating and binding of cholesterol as well as bile acids by the lactic acid bacteria. Promotion of bile acid excretion due to deconjugation to produce free bile acids was proposed as another mechanism for serum lipid improvement (Grundy, 1972). It is known that the serum cholesterol level decreases when a component suppresses resorption of bile acid in the intestine 
because the catabolism of cholesterol is promoted in the liver. Binding of cholesterol or bile acids was not investigated in the present studies, but a higher excretion of bile acids in feces, although not statistically significant $(P=0.068)$, was observed in the group fed bifidobacterium milk. Increased fecal output of neutral sterols and bile salts was observed in piglets fed L. reuteri (De Smet et al., 1998).

Surviving passage through the gastrointestinal tract is believed to be important for probiotics to function in the intestine (Gilliland and Walker, 1990; Salminen and von Wright, 1993). Very few studies have mentioned the survival of the bacterial cells supplemented to the diets in animal experiments. We noticed that lyophilized cells of lactobacilli and bifidobacteria died largely within 1 to $2 \mathrm{~d}$ after being combined with the diet, presumably due to the moisture of the diet. In the present studies, special attention was given to maintaining a higher survival of the bacterial cells by means such as employing dried diet materials, mixing the cells into diets just before administration, and replacing the diets daily.

$B$. longum strain BL1 was shown to survive at a high rate in artificial gastric juice at $\mathrm{pH} 3.0$ for 1.5 to $2 \mathrm{~h}$. Bacteria would contact $\mathrm{pH}$ values ranging from 2.0 to 8.0 in the stomach, depending upon whether or not food was being consumed (Hood and Zottola, 1988). Resisting exposure to $\mathrm{pH} 3$ for 1.5 to $2 \mathrm{~h}$ is considered one standard for low-pH tolerance of probiotic bacteria (Itoh, 1992). Surviving bacteria from the stomach would then contact bile in the small intestine. Multiplication of bifidobacteria in the small intestine should not be expected since the bacteria are obligately anaerobic (Mitsuoka, 1978). Tolerance to bile is thus a criterion for bifidobacteria to survive passage through the small intestine. The present strain was found to survive at a relatively high concentration of bile for 5 to $16 \mathrm{~h}$, which is assumed to be the usual time for food to pass through the small intestine. However, S. thermophilus and L. delbrueckii subsp. bulgaricus, the two most important organisms used for yogurt manufacture, were not actually observed in the intestinal tract because of their low tolerance for bile salts, low resistance to acid $\mathrm{pH}$, and rather selective requirements for sugars (Harvenaar and Minekus, 1996; Rasic and Kurmann, 1979). Strain BL1 was found to possess a strong bile salt hydrolase activity (unpublished results). The surviving cells of strain BL1 may thus function in cholesterol reduction probably by binding with cholesterol and bile acids, as well as by suppressing bile acid resorption by deconjugation.

It was noticed that intake of fermented milk does not always show similar effects in humans as in animals because of differences between species in the choles- terol metabolism mechanism (Friedewald et al., 1972; Kawase et al., 2000). Studies in humans, however, have resulted in contradictory outcomes. Hepner et al. (1979) carried out the first randomized crossover trial with 17 subjects and indicated a 5 to $9 \%$ lowering effect of serum total cholesterol by unpasteurized yogurt. Randomized, double-blind, and placebo controlled studies also demonstrated significant reductions in serum total cholesterol and LDL-cholesterol by a milk product fermented with Enterococcus faecium and two strains of S. thermophilus (Agerbkæk et al., 1995; Richelsen et al., 1996). Kiessling et al. (2002) observed that consumption of yogurt increased the serum concentration of HDL-cholesterol and lead to the desired improvement of the LDL/HDL cholesterol ratio. Kawase et al. (2001) demonstrated a suppressing effect on cholesterol uptake by a fermented milk supplemented with $S$. thermophilus in humans. However, studies employed fermented milks supplemented with $L$. acidophilus as well as other ordinary lactic acid bacteria resulted in lack of any effect (De Roos et al., 1999; Thompson et al., 1982). Studies conducted in human subjects are thus ambiguous regarding the effects of fermented dairy products on serum cholesterol concentrations. Further, although there were observations concerning in vitro cholesterol assimilation as well as cholesterol-lowering effect in animal experiments for bifidobacteria (Tahri et al., 1995; Beena and Prasad, 1997), hypocholesterolemic effect of bifidobacteria has not been demonstrated on human. To verify the effect of the bifidobacterium yogurt on human serum lipids as observed on rats, we carried out the present pilot human study. The bifidobacterium yogurt and the placebo yogurt have the same contents of milk fats, proteins, carbohydrates, and energy. The only difference was the presence or absence of the targeted bifidobacteria. A reduction trend in serum total cholesterol concentration was observed in the group of volunteers who consumed bifidobacterium yogurt, but the change was not significant. A significant reduction of total cholesterol after the 4 wk intake of the bifidobacterium yogurt was found for those subjects with initial total cholesterol values over $240 \mathrm{mg} /$ dl $(\mathrm{n}=9, P<0.05)$. We have no obvious explanation for the more notable effect in subjects with moderate hypercholesterolemia (serum total cholesterol $>240$ $\mathrm{mg} / \mathrm{dl}$ ) than those with serum total cholesterol in the range of 220 to $240 \mathrm{mg} / \mathrm{dl}$. This could perhaps be attributable to the small numbers of subjects in each group and the relatively high variation that occurred in the values of some subjects within each group. We could not exclude the influence of personal daily lifestyle on the changes of serum lipid levels, because each subject was advised to maintain ordinary living habits with- 
out great restriction during the experimental period. However, it should be noted that variability in effectiveness is commonly seen with lipid-lowering agents (Lees et al., 1977). Asaoka et al. (1996) also reported a selective lowering effect on serum total cholesterol in adult men administered a drink containing depolymerized sodium alginate, in which lowering was observed in those subjects with an initial total cholesterol level over $220 \mathrm{mg} / \mathrm{dl}$, but not in those with a normal level $(<220 \mathrm{mg} / \mathrm{dl})$.

Correlated reduction of LDL- and HDL-cholesterol was observed along with the decrease in total cholesterol, but statistical significance occurred neither for the whole group nor for the portion with moderate hypercholesterolemia (serum total cholesterol $<240$ $\mathrm{mg} / \mathrm{dl}$ ). The related changes of total cholesterol, LDLcholesterol, and HDL-cholesterol may support the hypothesis that the strain acts by promoting excretion of cholesterol and bile acid, rather than by affecting hepatic cholesterol synthesis.

The present results indicate the potential of the bifidobacterium yogurt in lowering serum total cholesterol, especially in those subjects with moderate hypercholesterolemia (serum total cholesterol $>240 \mathrm{mg} /$ dl). The borderline for the onset of medical therapy for serum total cholesterol has been recently raised from 220 to $240 \mathrm{mg} / \mathrm{dl}$ in Japan. The clinical importance of this yogurt is thus noteworthy, and research is being planned with more subjects and for longer terms in combination with nutrition instruction for further clarification.

\section{CONCLUSIONS}

The present study demonstrated that, as compared to traditional yogurt fermented with ordinary lactic acid bacteria, bifidobacterium yogurt fermented with a probiotic strain of Bifidobacterium longum BL1 and a drinking yogurt fermented with strain BL1 plus ordinary lactic acid bacteria were effective in improving serum lipids in rats and in humans with initial serum cholesterol level more than $240 \mathrm{mg} / \mathrm{dl}$, respectively. $B$. longum strain BL1, which possesses a high tolerance to gastric juice and bile acids and shows a strong bile salt hydrolase activity, is assumed to survive passage through the gastrointestinal tract and function in cholesterol reduction. These results indicate the potential of the probiotic effect of the Bifidobacterium fermented products on serum cholesterol reduction.

\section{ACKNOWLEDGMENTS}

We wish to thank Dr. M. Takase and Dr. T. Yaeshima of the Nutritional Science Laboratory, Morinaga
Milk Industry Co., Ltd., for their helpful advice and technical assistance.

\section{REFERENCES}

Agerbæk, M., L. U. Gerdes, and B. Richelsen. 1995. Hypocholesterolaemic effect of a new fermented milk product in healthy middle-aged men. Eur. J. Clin. Nutr. 49:346-352.

Aklain, A. S., S. Gonc, and S. Duzel. 1997. Influence of yogurt and acidophilus yogurt on serum cholesterol levels in mice. J. Dairy Sci. 80:2721-2725.

Anderson, K. M., W. P. Castelli, and D. Levy. 1987. Cholesterol and mortality. 30 years of follow-up from the Framingham study. J. Am. Med. Assoc. 257:2176.

Asaoka, T., H. Iwatsuka, and H. Minowa. 1996. Effect of "CHOLECUT," a drink containing depolymerized sodium alginate, on serum cholesterol levels in healthy males. Jpn. J. Nutr. Assess. 13:460-464.

Beena, A., and V. Prasad. 1997. Effect of yoghurt and bifidus yoghurt fortified with skim milk powder, condensed whey and lactosehydrolysed condensed whey on serum cholesterol and triacylglycerol levels in rats. J. Dairy Res. 64:453-457.

Bottazzi, V., C. Zacconi, E. Gonzaga, and M. Paladino. 1986. Absorption of cholesterol by intestinal lactic acid bacteria. Ann. Microbiol. 36:1-5.

Danielson, A. D., E. R. Peo, K. M. Shahani, A. J. Lewis, P. J. Whalen, and M. A. Amer. 1989. Anticholesteremic property of Lactobacillus acidophilus yogurt fed to mature boars. J. Anim. Sci. 67:966-974.

De Roos, N. M., G. Schouten, and M. B. Katan. 1999. Yoghurt enriched with Lactobacillus acidophilus does not lower blood lipids in healthy men and women with normal to borderline high serum cholesterol levels. Eur. J. Clin. Nutr. 53: 277-280.

De Smet, I., P. De Boever, and W. Versteaete. 1998. Cholesterol lowering in pigs through enhanced bacterial bile salt hydrolase activity. British J. Nutr. 79: 185-194.

Frick, M. H., O. Elo, K. Haapa, O. P. Heinonen, P. Heinsalmi, P. Helo, J. K. Huttunen, P. Kaitaniemi, P. Koskinen, and V. Manninen. 1987. Helsinki Heart Study: Primary-prevention trial with gemfibrozil in middle-aged men with dyslipidemia. Safety of treatment, changes in risk factors, and incidence of coronary heart disease. N. Engl. J. Med. 317:1237-1245.

Friedewald, W. R., R. I. Levy, and D. S. Fredrickson. 1972. Estimation of the concentration of low-density lipoprotein cholesterol in plasma, without use of the preparative ultracentrifuge. Clin. Chem. 18:499-502.

Gilliland, S. E., C. R. Nelson, and C. Maxwell. 1985. Assimilation of cholesterol by Lactobacillus acidophilus. Appl Environ. Micorbiol 49:377-381.

Gilliland, S. E., and D. K. Walker. 1990. Factor to consider when selecting a culture of Lactobacillus acidophilus as a dietary adjunct to produce a hypocholesterolemic effect in humans. J. Dairy Sci. 73:905-911.

Grundy, S. M. 1972. Treatment of hypercholesterolemia by interference with bile acid metabolism. Arch. Internal Med. 130:638648.

Harvenaar, R. and M. Minekus. 1996. Stimulated assimilation. Dairy Ind. Int. 61(9):17-23.

Hashimoto, H., K. Yamazaki, F. He, M. Kawase, M. Hosoda, and A. Hosono. 1999. Hypocholesterolemic effects of Lactobacillus casei subsp. casei TMC 0409 strain observed in the rats fed cholesterol contained diets. Anim. Sci. J. 72:90-97.

Hepner, G., R. Fried, S. St. Jeor, L. Fusetti, and R. Morin. 1979. Hypercholesterolemic effect of yoghurt and milk. Am. J. Clin. Nutr. 32:19-24.

Hood, S. K., and E. A. Zottola. 1988. Effect of low pH on the ability of Lactobacillus acidophilus to survive and adhere to human intestinal cells. J. Food Sci. 53:1514-1516.

Hosono, A., and T. Tono-oka. 1995. Binding of cholesterol with lactic acid bacterial cells. Milchwissenschaft 50: 556-560. 
Itoh, T. 1992. Functional benefits from lactic acid bacteria used in cultured milk. Anim. Sci. Technol. 63:1276-1289.

Kawase. M., H. Hashimoto, M. Hosoda, H. Morita, and A. Hosono. 2000. Effect of administration of fermented milk containing whey protein concentrate to rats and healthy men on serum lipids and blood pressure. J. Dairy Sci. 83:255-263.

Kawase, M., H. Hashimoto, M. Hosoda, H. Morita, and A. Hosono. 2001. Effect of administration of fermented milk with Streptococcus thermophilus TMC1543 on serum lipid levels induced by a high-cholesterol diet in adult subjects. Milchwissenschaft 56:496-499.

Kiessling, G., J. Schneider, and G. Jahries. 2002. Long-term consumption of fermented dairy products over 6 months increases HDL cholesterol. Eur. J. Clin. Nutr. 56(9):843-849.

Law, M. R, N. J. Wald, T. Wu, A. Hackshaw, and A. Bailey. 1994. Systematic underestimation of association between serum cholesterol concentration and ischaemic heart disease in observational studies: data from the BUPA study. Br. Med. J. 308:363-366.

Lees, A. M., H. Y. Mork, R. S. Lees, A. M. McCluskey, and S.M. Grundy. 1977. Plant sterols as cholesterol-lowering agents: clinical trials in patients with hypercholesterolemia and studies of sterol balance. Atherosclerosis 28:325-338.

Mabuchi, H. 1999. Primary and secondary prevention of atherosclerotic disease by lipid-lowering therapies. Nippon Rinsho 57:2807-2814.

Mann, G. V., and A. Spoerry. 1974. Studies of a surfactant and cholesterolemia in the Massai. Am. J. Clin. Nutr. 27: 464-469.

Mitsuoka, T. 1978. Intestinal Bacteria and Health. Harcourt Brace Jovanovich Japan Inc., Tokyo. Rasic, J. L., and J. A. Kurmann. 1979. Yogurt. Scientific Grounds Technology, Manufacture and Preparations. 2nd ed. Tech. Dairy Publ. House, Copenhagen, Denmark.
Richelsen, B., K. Kristensen, and S. B. Pedersen. 1996. Long term ( 6 months) effect of a new fermented milk product on the level of plasma lipoproteins - a placebo-controlled and double blind study. Eur. J. Clin. Nutr. 50:811-815.

Ross, R. 1993. The pathogenesis of atherosclerosis: a perspective for 1990s. Nature 362:801-809.

Salminen, S., and A. von Wright. 1993. Lactic Acid Bacteria. Marcel Dekker, Inc., New Yorker, NY.

St-Onge, M. P., E. R. Farnworth, and P. J. H. Jones. 2000. Consumption of fermented and nonfermented dairy products: effects on cholesterol concentrations and metabolism. Am. J. Clin. Nutr. 71:674-681.

Tahri K., J. Crociani, J. Ballongue, and F. Scheider. 1995. Effects of the three strains of bifidobacteria on cholesterol. Lett. Appl. Microbiol. 21:149-151.

Taranto. M. P., M. Medici, G. Perdigon, A. P. Ruiz Holgado, and G. F. Valdez. 1998. Evidence for hypocholesterolemic effect of Lactobacillus reuteri in hypercholesterolemic mice. J. Dairy Sci. 81:2336-2340.

Thompson, L. U., D. J. Jenkins, M. A. Amer, R. Reichert, A. Jenkins, and J. Kamulsky. 1982. The effect of fermented and unfermented milks on serum cholesterol. Am. J. Clin. Nutr. 36:1106-1111.

Usman, and A. Hosono. 2000. Effect of administration of Lactobacillus gasseri on serum lipids and fecal steroids in hypercholestrolemic rats. J. Dairy Sci. 83:1705-1711.

Yamamoto, A., H. Horibe, H. Mabuchi, T. Kita, Y. Matsuzawa, Y. Saito, N. Nakaya, T. Fujioka, H. Tenba, A. Kawaguchi, H. Nakamura, and Y. Goto. 1999. Analysis of serum lipid levels in Japanese men and women according to body mass index. Increase in risk of atherosclerosis in postmenopausal women. Research Group on Serum Lipid Survey 1990 in Japan. Atherosclerosis 143:55-73. 